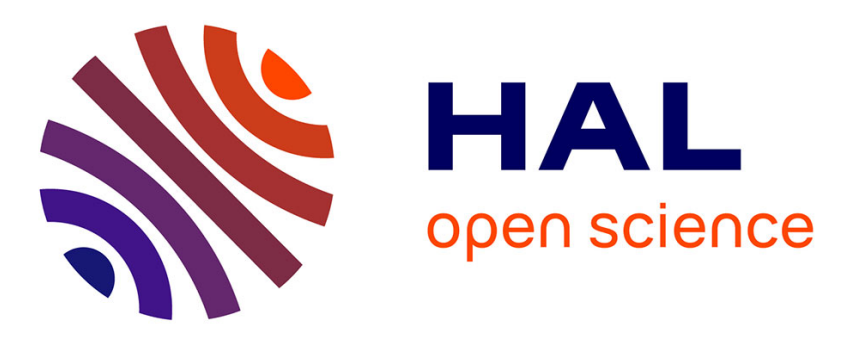

\title{
Nanofibres of CA/PAN with high amount of carbon nanotubes by core-shell electrospinning
}

Milana Lisunova, Attila Hildmann, Benjamin Hatting, Vitaliy Datsyuk, Stephanie Reich

\section{- To cite this version:}

Milana Lisunova, Attila Hildmann, Benjamin Hatting, Vitaliy Datsyuk, Stephanie Reich. Nanofibres of CA/PAN with high amount of carbon nanotubes by core-shell electrospinning. Composites Science and Technology, 2010, 70 (11), pp.1584. 10.1016/j.compscitech.2010.07.001 . hal-00666481

\section{HAL Id: hal-00666481 \\ https://hal.science/hal-00666481}

Submitted on 5 Feb 2012

HAL is a multi-disciplinary open access archive for the deposit and dissemination of scientific research documents, whether they are published or not. The documents may come from teaching and research institutions in France or abroad, or from public or private research centers.
L'archive ouverte pluridisciplinaire HAL, est destinée au dépôt et à la diffusion de documents scientifiques de niveau recherche, publiés ou non, émanant des établissements d'enseignement et de recherche français ou étrangers, des laboratoires publics ou privés. 


\section{Accepted Manuscript}

Nanofibres of CA/PAN with high amount of carbon nanotubes by core-shell electrospinning

Milana Lisunova, Attila Hildmann, Benjamin Hatting, Vitaliy Datsyuk, Stephanie Reich

PII: S0266-3538(10)00258-7

DOI: 10.1016/j.compscitech.2010.07.001

Reference: CSTE 4755

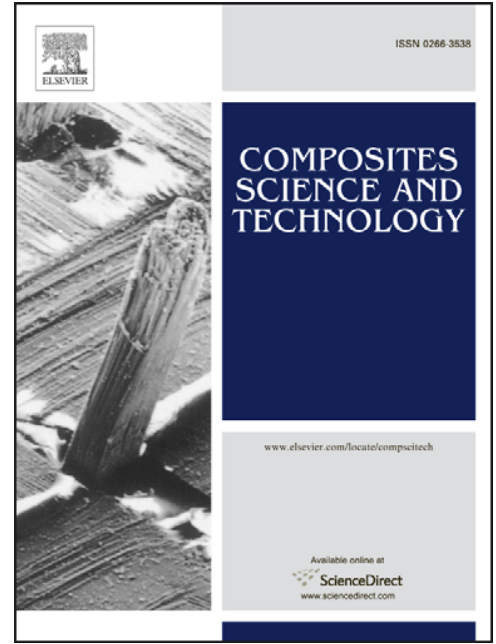

To appear in:

Composites Science and Technology

Received Date:

25 March 2010

Revised Date:

25 June 2010

Accepted Date:

4 July 2010

Please cite this article as: Lisunova, M., Hildmann, A., Hatting, B., Datsyuk, V., Reich, S., Nanofibres of CA/PAN with high amount of carbon nanotubes by core-shell electrospinning, Composites Science and Technology (2010), doi: 10.1016/j.compscitech.2010.07.001

This is a PDF file of an unedited manuscript that has been accepted for publication. As a service to our customers we are providing this early version of the manuscript. The manuscript will undergo copyediting, typesetting, and review of the resulting proof before it is published in its final form. Please note that during the production process errors may be discovered which could affect the content, and all legal disclaimers that apply to the journal pertain. 
Nanofibres of CA/PAN with high amount of carbon nanotubes by core-shell electrospinning

Milana Lisunova, Attila Hildmann, Benjamin Hatting, Vitaliy Datsyuk, Stephanie Reich Freie Universität Berlin,

Fachbereich Physik, Arnimallee 14, 14195 Berlin, Germany

* Corresponding author:

E-mail adress: milana.lisunova@fu-berlin.de

Tel.: +04930 83852155 Fax.: +0493083856081 


\begin{abstract}
We prepared polyacrylonitrile (PAN) and cellulose acetate (CA) based nanofibres with high amount of carbon nanotubes (CNTs) by core-shell electrospinning. Atomic force microscopy (AFM) and transmission electron microscopy (TEM) were used to evaluate the morphology and structure of the electrospun nanofibres. Raman spectroscopy (Raman) and TEM indicate alignment of CNTs in the polymer fibres. Core-shell electrospinning improved the distribution and uniformity of the fibres. The loading of carbon nanotubes showed better thermal stability.
\end{abstract}

\title{
Keywords:
}

A: Carbon nanotubes; A: Polymers; A: Fibres; E: Electro-spinning; B: Thermal properties

\section{Introduction}

Electrospinnning of cellulose and derived materials is a well known and well developed process for the production of nanofibres. Such fibres are used as filters, drugdelivery vehicles, and scaffolds for tissue cultures [1,2]. Electrospun cellulose acetate (CA) nanofibres with conductive fillers such as carbon nanotubes (CNTs) [3] are also interesting for electro-active paper sensor and actuator [1]. CA/CNTs - based composites are promising materials for sensors, electromagnetic shielding materials, and antistatic films [4], due to the unique electronic, thermal, optical, and mechanical properties of CNTs [3]. Additionally, carbon nanotubes were considered for a wide range of applications in nanotechnology, because of their superior material properties such as low density and high aspect ratio [5]. Electrospinning CA solution with a filler fraction greater than $4 \%$ wt. resulted in the formation of short and beaded fibres [4]. 
Elctrospinning CA with high concentration of CNTs was limited by viscosity [6]. Incorporating a high fraction of filler in electrospun CA nanofibres was achieved by adding polyacrylonitrile (PAN) or polyethylene oxide (PEO) [7]. Such blending of polymers leads to the enhancement of the homogeneity and the stability of the electrospun jet, but the immiscibility of polymers is problematic [7]. Core-shell electrospinning seems to be promising for combining immiscible polymer solutions while keeping their individual properties[8-12].

In this work we report the production of core-shell nanofibres based on cellulose acetate and polyacrylonitrile filled with a large fraction of carbon nanotubes. We investigate and discuss the morphology, structure and thermal stability of the nanofibers.

\section{Experimental}

\subsection{Materials}

The CNTs used in this work were Multiwalled carbon nanotubes (MWCNTs) "Baytubes C150P" supplied by Bayer Materials Science AG. The MWCNTs were synthesized by the chemical vapour deposition (CVD). Statistical study of the TEM images (Figure 1) of CNT showed they are multiwalled nanotubes with an outer diameter $d 20-40 \mathrm{~nm}$ and their length $l_{n}$ is about tens of microns $(\mu \mathrm{m})$. The density of the MWCNT walls was estimated according to the ENI $8060 \rho_{f}=1.2-1.7 \mathrm{~g} / \mathrm{cm}^{3}$. 


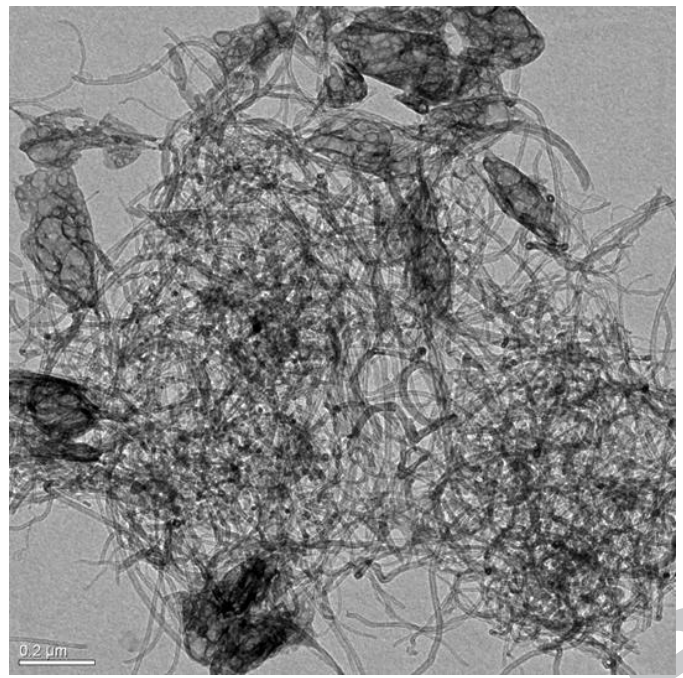

Fig. 1. Typical TEM image of multiwalled carbon nanotubes

Cellulose acetate (CA, with density $\rho_{i n}=1.184 \mathrm{~g} / \mathrm{cm}^{3}$, melting temperature $T_{m}$ $\left.=280{ }^{0} \mathrm{C}\right)$ and polyacrylonitrile $\left(\mathrm{PAN}\right.$, with density $\rho_{\text {in }}=1.184 \mathrm{~g} / \mathrm{cm}^{3}$, melting temperature $T_{m}=317{ }^{0} \mathrm{C}$ ) were obtained from Aldrich. The $N, N$-dimethyl-formamide (DMF), dimethyl-acetamide (DMAc) and acetone (Ac) were purchased from Aldrich and used without any purification as solvents with boiling points $T_{b}=153{ }^{0} \mathrm{C}, T_{b}=164$ ${ }^{0} \mathrm{C}$ and $T_{b}=56{ }^{0} \mathrm{C}$, respectively.

\subsection{Electrospinning setup}

A schematic illustration of the experimental setup for electrospinning is presented in Fig. 2. Coaxial needles containing the core and shell precursor solutions were used to produce the fibres. $10 \%$ wt. of PAN in DMF with $15 \%$ wt. of CNTs was used to produce the PAN/CNTs fibres. 15w\% of CA in DMAc/acetone (2 to 1) and $10 \%$ wt. of PAN in DMF with $35 \%$ wt. of CNTs were used to produce the core and shell of the CA/PAN-CNTs nanofibres, respectively. The fraction of nanotubes in both samples is given to the polymer matrix. The flow rates of both solutions were $0.2 \mathrm{ml} / \mathrm{h}$. The tip of 
the core needle and the collector were connected to the high-voltage power supply. The tip-to-collector distance was $15-20 \mathrm{~cm}$, and the electrical potential difference was $30 \mathrm{kV}$.

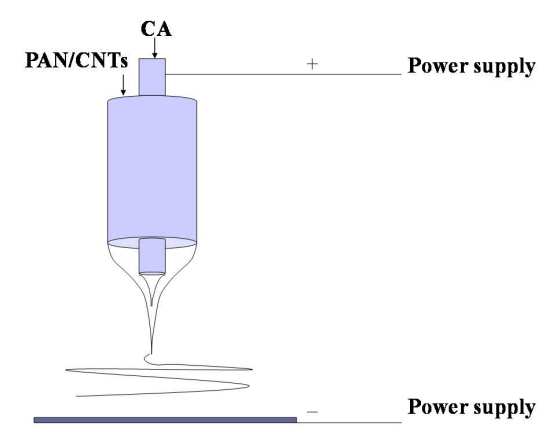

Fig. 2. Schematic illustration of the electrospinning setup

\subsection{Characterization}

The calorimetry experiments were performed using a differential-scanning calorimeter DSC-PT1 (Linseis Messgeräte $\mathrm{GmbH}$ ), equipped with sub-ambient temperature operation. The heat flux and temperature were calibrated with a sapphire standard for the same scan rate as used in our experiments. The measurements were carried out in the temperature range of $350-678 \mathrm{~K}$, in the heating mode. The samples were encapsulated into small-volume aluminum hermetic pans. In order to keep the melt peaks as narrow as possible, the masses of samples were only 2-3 mg.

The structure of MWCNTs and the MWCNTs/PAN nanofibres were examined using the TEM (JEM $100{ }^{\circ} \mathrm{C}$, Jeol, operating at accelerating voltage $100 \mathrm{kV}$ ). The surface morphology of the nanofibres was studied by atomic force microscopy (AFM, Park AFM, Schaefer Technologie GmbH). Raman spectroscopic analysis of MWCNTs/PAN nanofibres was carried out using the Xplora Raman spectrometer (Horiba Scientific), under ambient conditions. The $514.5 \mathrm{~nm}$ line from an $\mathrm{Ar}^{+}$laser was 
used for excitation at a power of $6 \mathrm{~mW}$. Ultrasonication was conducted using a sonifier equipped with a cup horn Sonopuls HD3100 (Bandelin), which was operated at a frequency of $10 \mathrm{kHz}$ with output power $100 \mathrm{~W}$. The CNTs in polymer solution were sonicated for $30 \mathrm{~min}$.

\section{Results and discussions}

\subsection{Morphology}

Figure 3 presents the already introduced TEM images of the PAN/CNTs $(a, c)$ and CA/PAN-CNTs (b, d) composites. The fraction of nanotubes is the same in both samples (15 wt\%); the fibres were prepared by electrospinning (Fig. 3 (a, c)) and coreshell electrospinning (Fig. 3 (b, d)). Examination of the images reveals that the MWCNTs are homogeneously distributed inside the polymeric fibres and aligned along the axes of the nanofibres. The alignment of CNTs by electrospinning was also investigated by Gogotsi et.al. [13-15]. According to their hypothesis alignment of CNTs in the nanofibre occurs through two mechanisms: flow-confinement-and charge-induced alignment during the elctrospinning process.


Fig. 3. TEM images of the PAN/CNTs $(a, c)$ and CA/PAN-CNTs $(b, d)$ nanofibres 
Investigation of the surface morphology by AFM (see Fig. 4) shows that core-shell electrospinning leads to the formation of more smooth fibres compared to the fibres produced by electrospinning in Fig.4 (a). Moreover, it is clearly proved that the coreshell structure reduced the amount of beads and defects. The effect of core-shell electrospinning on the distribution and packing of the fibre was also reported by Han [9]. Well defined and uniform fibres were observed for the combination of Nylon-6 (core)polyurethane (shell) [9], poly(ethylene oxide) (shell) and polysulfone (core) [10], poly(methyl methacrylate) (core) and Poly(3-hexylthiophene) (shell) [11], poly(2methoxy-5-(2-ethylhexyloxy)-1,4-phenylenevinylene) (core) and poly(vinyl pyrrolidone) (shell) [ 12].

The estimated diameters were about 40-50 nm PAN/CNTs and $150 \mathrm{~nm}$ for the CA/PAN-CNTs nanofibres. The thicker diameter of the CA/PAN-CNTs results from the structural organization with an inner diameter of CA (core) around $60 \mathrm{~nm}$ and outer layer of PAN-CNTs (shell) around $50 \mathrm{~nm}$.
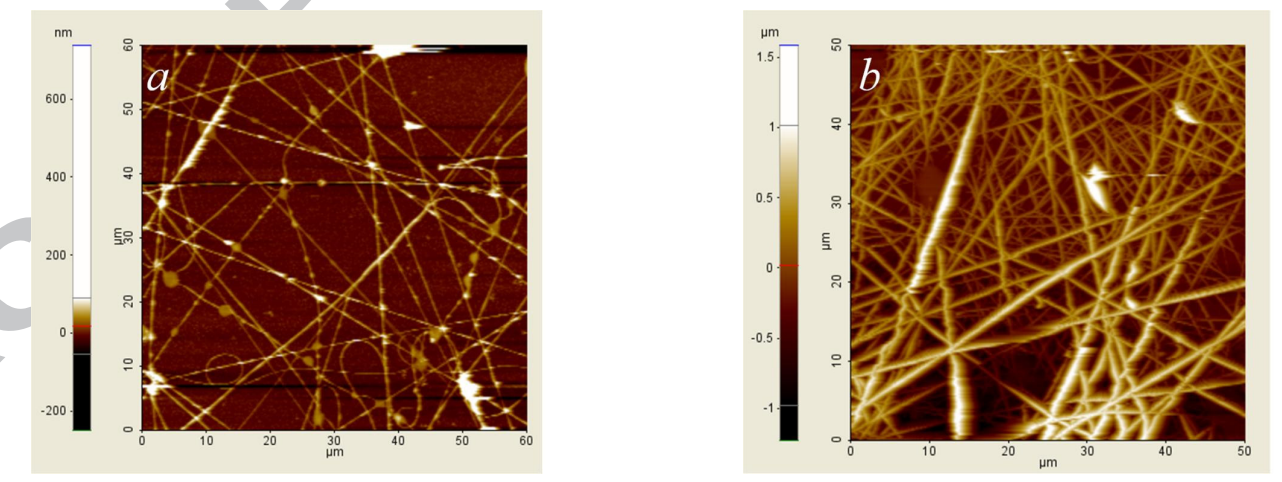

Fig. 4. AFM images of the PAN/CNTs $(a)$ and CA/PAN-CNTs $(b)$ nanofibres

The Raman spectra of the CA/PAN-CNTs nanofibres in Fig.5 confirmed the embedding of CNTs. The strongest peak at $1580 \mathrm{~cm}^{-1}$ (G peak), corresponds to 
scattering on $\mathrm{sp}^{2}$ bounded carbon atoms combined into graphite clusters. The D peak centered at $1350 \mathrm{~cm}^{-1}$ is characteristic of the scattering on disordered graphite-like carbon clusters ( $\mathrm{sp}^{3}$ bonded carbon atoms). The intensity of the $\mathrm{G}$ and $\mathrm{D}$ bands is highest when the polarization is parallel to the fibre axis while it is lowest when it is perpendicular. Such reduction of the intensity of Raman signals indicates that the carbon nanotubes are aligned preferentially along the fibre axis [16-19].

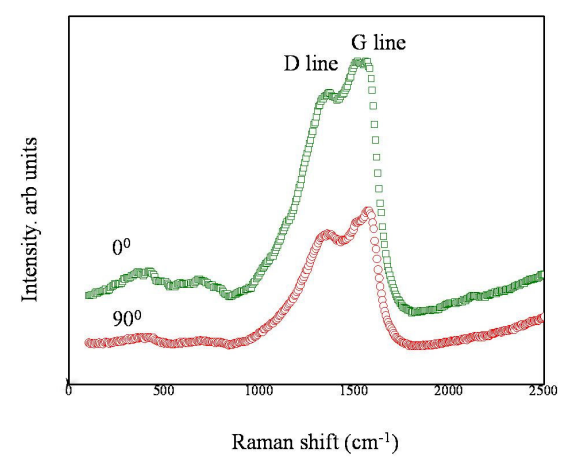

Fig. 5. Raman spectra of CA/PAN-CNTs nanofibres for the polarization parallel ( $\square$ ) and perpendicular $(\circ)$ to the fibre axis

\subsection{DSC of electrospun nanofibres}

Figure 6 compares the DSC curves for fibres made for PAN (1), CA (2) and PAN/MWCNTs (3) and CA/PAN-CNTs (4) composites (scan rate $10 \mathrm{~K} / \mathrm{min}$ ). The exothermic peaks of the PAN, PAN/MWCNTs and PAN/CA/MWCNTs electrospun nanofibres $\left(310-320{ }^{0} \mathrm{C}\right)$ are attributed to the melting point of PAN. The melting temperature of PAN slightly increases $(10 \mathrm{~K})$ with MWCNTs incorporation which is probably due to the good dispersion of MWCNTs and the large contact area of the MWNTs and PAN molecules. 
The exothermic peak within the range $350-360{ }^{\circ} \mathrm{C}$ observed in CA and CA/PANCNTs corresponds to the crystallization temperature $T_{c}$ of CA or the molecular rearrangement in the fibre. The degradation temperature of CA/PAN-CNTs is higher than pure CA. This is mainly due to the structural organization of the fibres. The CA/PAN-CNTs consists of CA core covered by thin layer of PAN with CNTs, which increases physical barrier for thermal transmission of the confined molecules during the thermal degradation of the fibres (see schematic representation in Fig. 6, b) [5, 20].
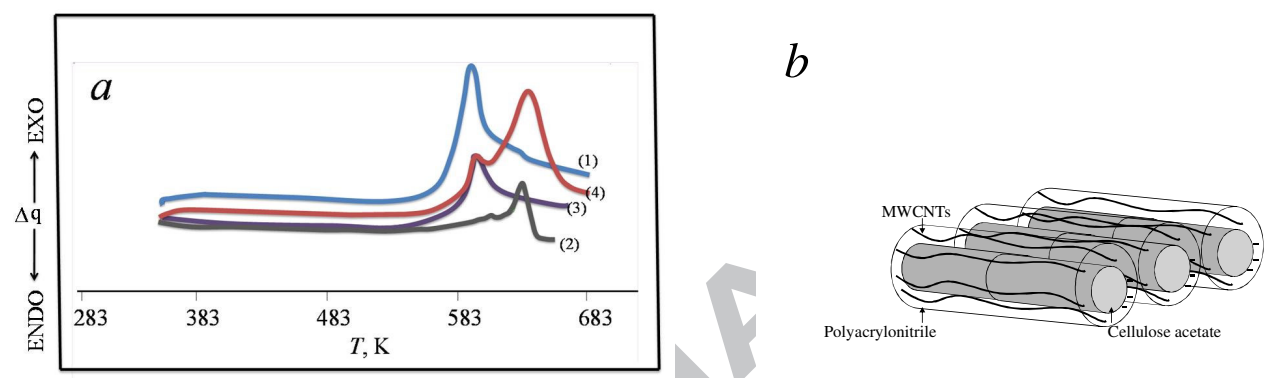

Fig. 6. DSC curves of PAN (1), CA (2), PAN/CNTs (3) and CA/PAN-CNTs (4) at 10 $\mathrm{K} / \mathrm{min}$ heating rate $(a)$. Schematic representation of CA/PAN-CNTs nanostructure $(b)$

DSC curves of CA/PAN-CNTs obtained with a heating rate of 10,15 and 20 $\mathrm{K} / \mathrm{min}$ are presented in Fig.7. The dependence between the temperature at which the reaction rate attain a maximum value and the heating rate is described by the Kissinger relationship

$$
E_{a}=-R\left(\delta \ln \beta / T^{, 2}\right) /\left(\delta 1 / T^{\prime}\right)
$$

where $T$ is the temperature at peak maximum in the DSC response curve, $\beta$ represents the heating rate of the sample and $R$ is the universal gas constant. 


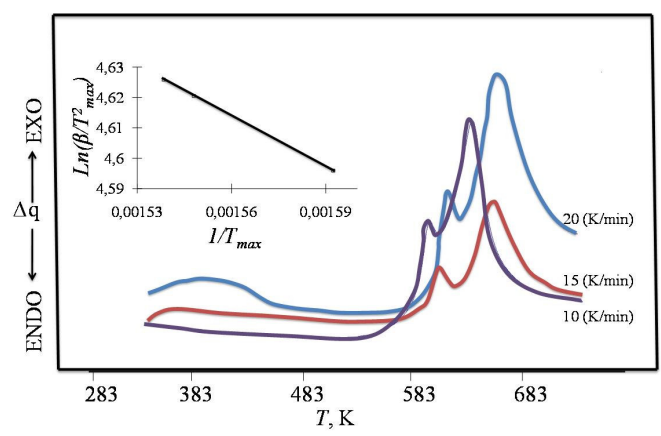

Fig. 7. DSC curves of CA/PAN-CNTs nanofibres at $10,15,20 \mathrm{~K} / \mathrm{min}$ heating rates. The insert shows Kissinger plot for the second peaks of CA/PAN-CNTs nanofibres

The activation energy of degradation $\Delta E_{a}$ of PAN increases with CNTs loading (see Table 1). This result can be explained by the energy barrier numbers in the transport process; it is in agreement with previously reported data for sodium aluminum hydride and lithium aluminum hydride composites filled by CNTs. $\Delta E_{a}$ of CA slightly increases, i.e., CNTs are not included into the morphological structure of CA. The improved $\Delta E_{a}$ of PAN also confirms the deagglomeration and uniform distribution of CNTs [20-23].

Table 1. The activation energies for electrospun PAN, CA, PAN/CNTs and CA/PAN-CNTs.

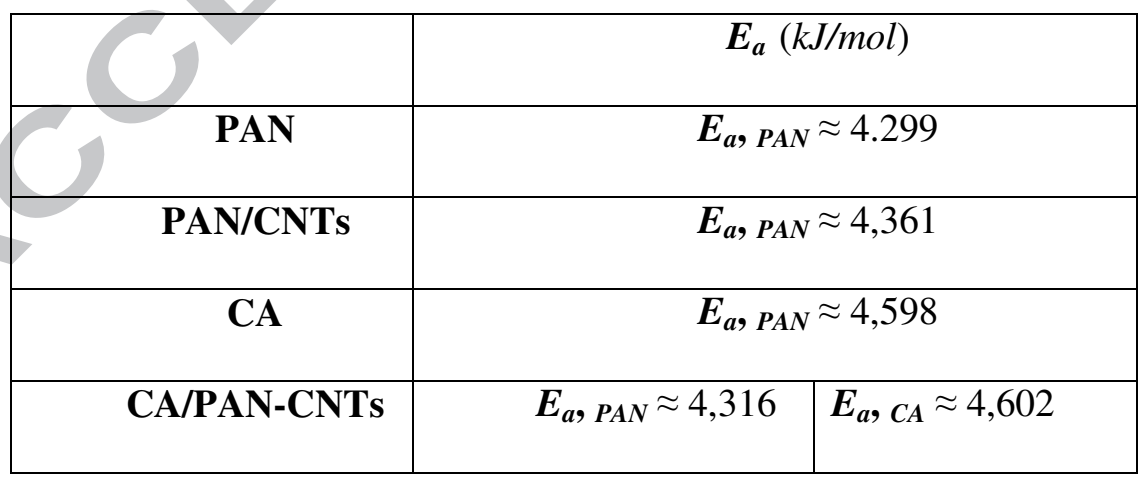




\section{Conclusion}

Core-shell electrospinning improves the homogeneous distribution and uniformity of fibres based on PAN and CA with a high amount of CNTs. DSC data reveal an increase of the degradation temperature for CA and PAN with CNTs loading. The improved thermal properties possibly reflect the deagglomeration and alignment of CNTs in the polymer fibres. The enhancement of activation energies of degradation of polymer fibres are believed to be due to the ordered structure of CNTs.

\section{Acknowledgement}

This work was supprovied by the BMBF Project Format CNTherm. The authors thank Solve Soren for the TEM investigation.

\section{References}

[1] Liu H., Hsieh Y-L. Ultrafine fibrous cellulose membranes from electrospinning of cellulose acetate. J Polym Sci B: Polym Phys 2002; 40: 21192129.

[2] Pankonien AM. Electrospinning of cellulose and carbon nanotubecellulose fibers for smart applications. Undergraduate Thesis, University of Texas, Department of Aerospace engineering, 2008.

[3] Reich S, Thomsen C, Maultzsch J. Carbon nanotubes: basic concepts and physical properties, Berlin, Wiley-VCH, 2004.

[4] Rubenstein D, Han D, Goldgraben S, El-Gendi H. , Gouma P, Frame M D. Bioassay Chamber for Angiogenesis with Perfused Explanted Arteries and Electrospun Scaffolding. Microcirculation 2007; 14 (7): 723-737.

[5] Lisunova MO, Mamunya YP, Lebovka NI, Melezhyk AV. Percolation behaviour of ultrahigh molecular weight polyethylene/multi-walled carbon 
nanotubes composites. Eur Polym J 2007; 43: 949-958.

[6] Seoul C., Kim Y-T. Electrospinning of Poly(vinylidene fluoride)/dimethylformamide solutions with carbon nanotubes. J. Polym. Sci. B: Polym. Phys 2003; 41:1572.

[7] Chen L, Bromberg L, Hatton TA, Rutlenge GC. Electrospun cellulose acetate fibers containing chlorhexidine as a bactetricide. Polymer 2008; 48:1266-1275.

[8] Lallave M, Bedia J, Ruiz-Rosas R, Rodriguez-Mirasol J, Cordero T, Otero JC, Marquez M, Barrero A, Loscertales IG. Filled and Hollow carbon nanofibers by coaxial electrospinning of alcell lignin without binder polymers. Adv Mater 2007; 19: 4292-4296.

[9] Han X, Huang Z, He C, Liu L. Preparation and characterization of coreshell structured nanofibers by coaxial electrospinning. High Perform Polym 2007; 19: $147-159$.

[10] Sun Z, Zussman E, Yarin AL, Wendorff JH, Greiner A. Compound coreshell polymer nanofibers by co-electrospinning. Adv Mater 2003; 15 (22): 1929-1932.

[11] Kuo C, Wang CT, Chen WC. Poly(3-hexylthiophene)/poly(methyl methacrylate) core-shell electrospun fibers for sensory applications. Macromol Symp 2009; 279: 41-47.

[12] Li D, Babel A, Jenekhe SA, Xia Y. Nanofibers of Conjugated polymers prepared by electrospinning with a two-capillary spinneret. Adv Mater 2004; 16 (22): 2062- 2066. 
[13] Ko F, Gogotsi Y, Ali A, Naguib N, Ye H, Yang G, Li C, Willis P. Electrospinning of continuous carbon nanotube-filled nanofiber yarns. Adv Mater 2003; 15 (14): 1161-1165.

[14] Lakoubovskii K. Techniques of aligning carbon nanotubes. Cent Eur J Phys 2009; 7(4): 645-653.

[15] Zhou W, Wu Y, Wie F, Luo G, Qian W. Elastic deformation of multiwalled carbon nanotubes in electrospun MWCNTs-PEO and MWCNTsPVA nanofibers. Polymer 2005; 46:12689- 12695.

[16] Anglaret E, Righi A, Sauvajol JL, Bernier, Vigolo B, Poulin P. Raman study of orientational order in fibers of single wall carbon nanotubes. Physica B 2002; 323: 38-43.

[17] Liu T, Kumar S. Quantative characterization of SWNT orientation by polarized Raman spectroscopy. Chem Phys Lett 2003; 378: 257-262.

[18] Salalha W, Dror Y, Khalfin RL, Cohen Y, Yarin AL, Zussman E. Singlewalled carbon nanotubes embedded in oriented polymeric nanofibers by electrospinning Langmuir 2004;20: 9852-9855.

[19] Rao AM, Saito R. Polarized Raman study of aligned multiwalled carbon nanotubes. Phys Rev Lett 2000; 84 (8): 1820-1823.

[20] Lebovka N, Dadakova T, Lysetskiy L, Melezhyk O, Puchkovska G, GavrilkoT, Barane J, Drozd M. Phase transitions, intermolecular interactions and electrical conductivity behavior in carbon multiwalled nanotubes/nematic liquid crystal composites. J Mol Struct 2008; 887:135-143. 
[21] Gong XY, Liu J, Baskaran S, Voise RD, Young JS. Surfactant-assisted processing of carbon nanotube/polymer composites. Chem Mater 2000; 12: $1049-1052$.

[22] Cadek M, Coleman JN, Barron V, Hedicke K, Blau WJ. Morphological and mechanical properties of carbon-nanotube-reinforced semicrystalline and amorphous polymer composites. Appl Phys Lett 2002; 81:5123.

[23] Kim HS, park BH, Yoon JS, Jin H-J. Thermal and electrical properties of poly(l-lactide)-graft-multiwalled carbon nanotube composites. Eur Polym J 2007; 5: 1729-1735. 


\section{Figure captions}

Fig. 1. Typical TEM image of multiwalled carbon nanotubes

Fig. 2. Schematic illustration of the electrospinning setup

Fig. 3. TEM images of the PAN/CNTs $(a, c)$ and CA/PAN-CNTs $(b, d)$ nanofibres

Fig. 4. AFM images of the PAN/CNTs (a) and CA/PAN-CNTs $(b)$ nanofibres

Fig. 5. Raman spectra of CA/PAN-CNTs nanofibres for the polarization parallel ( $\square$ ) and perpendicular( $($ ) to the fibre axis

Fig. 6. DSC curves of PAN (1), CA (2), PAN/CNTs (3) and CA/PAN-CNTs (4) at $10 \mathrm{~K} / \mathrm{min}$ heating rate $(a)$. Schematic representation of CA/PAN-CNTs nanostructure $(b)$

Fig. 7. DSC curves of CA/PAN-CNTs nanofibres at 10, 15, $20 \mathrm{~K} / \mathrm{min}$ heating rates. The insert shows Kissinger plot for the second peaks of CA/PAN-CNTs nanofibres

Table1. The activation energies for electrospun PAN, CA, PAN/CNTs and CA/PAN-CNTs. 